\title{
Analysis of rail-sea intermodal transportation market in Ningbo in the context of the marine economy demonstration areas
}

\author{
HUANG Pingping ${ }^{1}$ LAN Gengze ${ }^{2}$ SUN Jianhong ${ }^{3}$ \\ ${ }^{1}$ HUANG Pingping, School of Business, Ningbo University, P. R. China, 315211.Email: huangpingping@ hotmail.com \\ ${ }^{2}$ LAN Gengze, College of the humanities, Jilin University, P. R. China, 130012.Email: langz0210@mails.jlu.edu.cn \\ ${ }^{3}$ Corresponding author: SUN Jianhong, School of Business, Ningbo University, P. R. China, 315211. Email: \\ sunjianhong@nbu.edu.cn
}

Fund Project :modern Senior service industry development research center on Ningbo People's Government and Chinese Academy of Social Sciences Strategic Cooperation Project, 2011 project (project name:Research on tbe constructing of Ningbo waterway service system under the background of marine economic modernization; project Numbers: NZKT201110)

\begin{abstract}
Ningbo is facing with the opportunities and challenges in the context of the policy on marine economy demonstration area in Zhejiang. There is close relationship between the development of rail-sea intermodal transportation and the city's sustainable development. This paper will first analyze the status quo and the current problems of Ningbo sea-rail combined transport. Some suggestions of the expansion of hinterland range are given subsequently based on deeply takes apart the main problems on hinterland of the port of Ningbo, and followed by the concluding remarks.
\end{abstract}

Keywords: Ningbo; rail-sea intermodal transportation; market; analysis

\section{Introduction}

The State Council has officially approved the policy on Zhejiang Ocean Economic Development Demonstration Area in February 2011. As the core of the Marine Economic Development Demonstration Zone, Ningbo will face unprecedented opportunities. Meanwhile, it is facing fierce competition, particularly in the context of The 12th Five Year Plan which clearly focused on promoting the development of Zhoushan Islands. However, Ningbo can give full play to comparative advantages. Take combined rail and sea transport as an example, the development in Zhoushan need some time, while Ningbo has good foundation conditions.

Coastal cities will re-shuffle under the background. To widen its hinterland range, Ningbo should vigorously develop rail-sea intermodal transportation. The paper focuses on the problems of ail-sea intermodal transportation in Ningbo based on the analysis for status in quo and will conclude with recommendations related to the outreach of the hinterland.

\section{2. current situation of Container rail-sea intermodal transport in Ningbo}

Container transportation in China has entered a vigorous period of development, which needs coordination and cooperation in the process of multi-modal transportation.

Ningbo started late on rail-sea intermodal transport compared with some domestic ports. Therefore, the city does its best to create a good environment for the development of rail-sea intermodal transport, for instance, promulgated a series of special subsidy policies. 
In this sense, rail-sea intermodal transport has developed quickly. The development of rail-sea intermodal transportation in Ningbo recent years are shown in Table 1.

Table 1 Development of Ningbo's rail-sea intermodal transport

\begin{tabular}{|c|c|c|c|c|}
\hline Years & 2009 & 2010 & 2011 & 2012 \\
\hline $\begin{array}{c}\text { container } \\
\text { throughput / } \\
\text { Million TEU }\end{array}$ & 1042.3 & 1300.2 & 1451 & 1567.1 \\
\hline $\begin{array}{c}\text { Sea and } \\
\text { railway } \\
\text { transport / } \\
\text { million TEU }\end{array}$ & 0.0169 & 2.8139 & 4.666 & 5.9725 \\
\hline $\begin{array}{c}\text { Sea and } \\
\text { railway } \\
\text { transport } \\
\text { proportion /\% }\end{array}$ & 0.0016 & 0.22 & 0.32 & 0.38 \\
\hline
\end{tabular}

As shown in Table 1, the container volume has reached 59,700 TEU in 2012, an increase of 35 times more than 2009. It is predicted that in 2015, sea and railway transport volume in the form of container will reach 300,000 TEUs, accounting for $1 \%$ of the port's container throughput. Figure 1 shows although the small proportion of sea and railway transport now, the development presents an ascending trend.

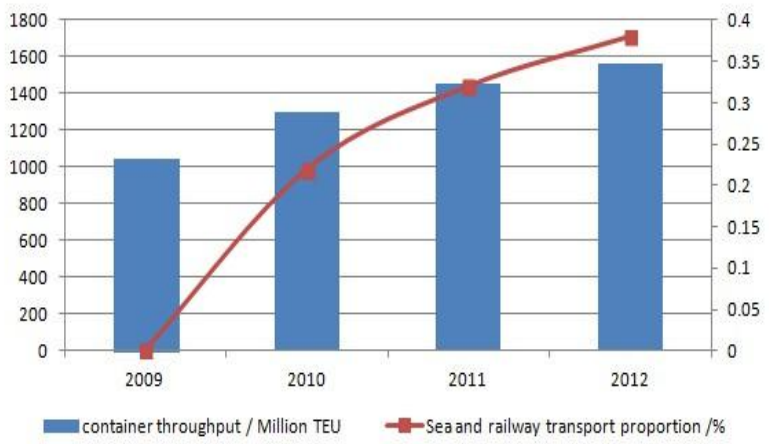

Fig.1: Development of Ningbo's sea-rail combined transport during 2009-2012 year

\section{3. market analysis}

\subsection{Development potential of Ningbo's rail-sea intermodal transportation}

Rail-sea intermodal transportation in some big container terminals, such as Shanghai, Dalian, Lianyungang, has developed to a certain scale.According to the proportion of rail-sea intermodal transportation in 2012, Port of Dalian and Lianyungang was significantly higher than the national average which is $1.87 \%$, the proportion of the ports are $5 \%$ and $6.04 \%$ respectively. Ningbo started late, but compared to neighboring ports, it has excellent conditions.

First, Port of Ningbo has excellent location and rich resources. On one hand, the port not only connect the other coastal ports ,also cover the entire eastern China and the developed economy along the Yangtze river basin directly through multimodal transportation; on the other hand ,the international main channel(e.g. Busan, South Korea, Hong Kong, Singapore, etc ) are within 1000 nautical miles. Therefore, the good geographical location makes the port an ideal distribution center for the Americas, Oceania and South America. Meanwhile, Ningbo provides necessary hardware equipment for the development of rail-sea intermodal transportation. At present, the world's top 20 shipping companies have logged in Port of Ningbo and the existing 228 container routes not only make up for the lack of routes of Shanghai ,also enhances the ability in the fierce competition of goods.

Secondly, Port of Ningbo has economically developed hinterland market. Yangtze River Delta where Ningbo located is China's fastest-growing economy and the accelerated process of economic integration is improving the region's influence .In addition, China's WTO accession and integrated with the world economy are good to the opening of the international and domestic markets.

\subsection{Analysis of hinterland expansion of rail-sea intermodal transportation in Ningbo}

There is close relationship between a port and its hinterland. 
There are three major groups of container hub port in coastal areas which including Yangtze River Delta, Pearl River Delta, and the Bohai Sea. Shanghai, Ningbo and Suzhou are the main container ports of Yangtze River Delta. Direct hinterland of the area including Shanghai, Jiangsu and Zhejiang, indirect hinterland are north of Anhui, Jiangxi, Hubei, southern areas of Henan and Shanxi .Because of cost advantage ,Shaanxi, north of Sichuan, Chongqing, Gansu, Qinghai, Xinjiang, Tibet and other regions are the potential hinterland of the three major port groups.

\subsubsection{Current situation of Ningbo's hinterland}

Direct hinterlands of Ningbo including Jiangsu, Zhejiang and Shanghai; Furthermore, the direct hinterland are Zhoushan, Shaoxing, Jinhua, Lishui, Hangzhou and together with the economic zone under the jurisdiction of Ningbo、 Taizhou and Wenzhou .

In terms of the crossed hinterland of Ningbo and Shanghai, there is Hangzhou, as well as the economic Zone under the jurisdiction of the Hangzhou-Jiaxing-Huzhou plain. In addition, Jiangsu, Anhui, Jiangxi, Hubei, Hunan, Sichuan, Chongqing belong to the indirect economic hinterland.

\subsubsection{Existing Problems of widening Ningbo's hinterland range}

First of all, the hinterland is not broad enough. In the rapid development of foreign trade of Ningbo, the goods from Zhejiang, Jiangsu and Shanghai play a very important role. However, the goods from domestic feeder somewhat less than that of the three places and is limited to Shanghai, Taizhou, Wenzhou, Qingdao, Guangzhou and other coastal ports.

Second, container quantity from direct hinterland is limited. At present, most of the industries in Zhejiang are labor-intensive. While industrial structure will change dramatically with $R \& D$ institutions moving to the areas. The situation that focusing on the amount of product will be changed, which makes the supply of container volume stabilized.

Finally, the competition from neighboring ports is furious. Competition between ports is mainly from the competition of resources. Take Shanghai for example, it has more economic hinterland than Ningbo. To be exact, Shanghai's economic hinterland across provincial boundaries and extend to the inland while the supply of Ningbo mainly from the neighboring cities.

\subsubsection{Expansion of expected hinterland of rail-sea intermodal transportation in Ningbo}

Yangtze River Valley has always been China's most economically developed regions and is undoubtedly the focus of Ningbo's prospective hinterland to explore.In details, Zhejiang, Shanghai, Jiangsu, southern Anhui, eastern Jiangxi, Hubei, Hunan, Sichuan and Chongqing are the hinterlands that Ningbo need to expand. There is a figure followed showing the import and export of Ningbo's hinterland( Shanghai, Jiangsu ,Anhui, Zhejiang, Jiangxi ,Hubei, Hunan, Sichuan, Chongqing ).As shown in Figure 2, import and export trade of Ningbo's hinterland has increased significantly in the past three years especially Anhui and Chongqing, the latter even has an explosive growth.. The growth will undoubtedly bring enormous opportunities for the development of rail-sea intermodal transportation in Ningbo.

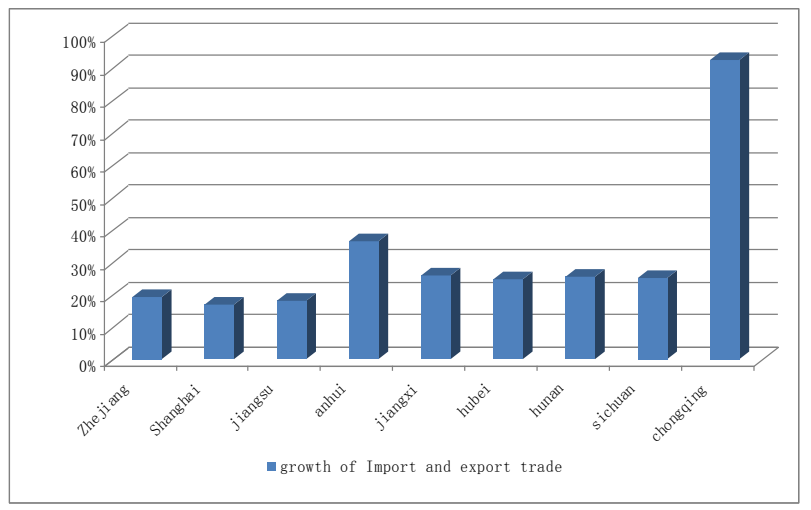

Fig.2: Import and export trade growth of Ningbo's hinterlands during 2010-2012 year

\subsection{Forecast of Ningbo's sea and railway transport market share}

During the last 10 years, Ningbo has made remarkable achievements in the world not only on the cargo throughput also on the container throughput. The cargo throughput was 453 million tons in 2012, which is 2.94 times more than the quantity of 2002, container throughput reached 5.67 million TEUs, which is 8.42 times that of 2002. 
Capacity of sea and railway transport of Ningbo has reached 59,700 TEUs in 2012 and the proportion has been to $0.38 \%$. The excellent port location, in addition, the rich resources and economically developed hinterlands make the sea and railway transport in Ningbo enjoys great potential of development. It is expected that Ningbo sea and railway transport will remain the growth rate of $30 \% \sim 50 \%$ by 2015 . The volume will reach $10 \sim 20$ million TEUs and the market share will increase from the current $0.38 \%$ to $0.5 \% \sim 0.9 \%$ based on the rate of growth.

\section{Recommendations about expanding Ningbo's rail-sea intermodal transportation hinterland}

\subsection{To perfect the collection and distribution systems, build multimodal transport network system}

Ningbo must design the intermodal network system before the target markets are accepted into the other intermodal network system.

In terms of the Port of Ningbo, it should study the development patterns of indirect hinterland and access to the sea on the basis of enhancing its immediate hinterland's service functions and strengthening infrastructure construction which is focusing on the Multi-modal transportation. Meanwhile the construction of dry port is also an important way of improving port accessibility.

\subsection{Intensify the development of key freight market}

Ningbo should focus Yangtze River that is the concentrated districts of hinterland as its key object to develop.Freight forwarding company should set up branches and cargo canvassing outlets for cities along the Yangtze River. Meanwhile, the deficiency of container terminal along the Yangtze River should be paid attention to and it makes Ningbo take the establishment of dry ports into consideration for the cities not along Yangtze River. In addition, harbor department of Ningbo can build collaborate relationship with strong freight forwarding companies on the construction of container terminal to promote the development of container transport market directly.

\subsection{Tap the potentiality of the port of Ningbo, Create self-brand}

Customers paid great attention to the brand and image of a port and good image plays a crucial role in attracting source of goods and opening up routes.

So Ningbo should pay attention to internal management and external services based on the purpose of services first, customer first. It can take actions for boosting competitiveness such as increasing the investment in equipment, accelerating the introduction of advanced management experience and strengthening personnel training and other measures.

\section{Conclusion}

The construction of marine economy demonstration area in Zhejiang Province has been a national strategy.In this context, Ningbo should grasp the challenges, as well as opportunities which may further maintain and advance the advantage of marine economy through the development of sea and railway transport. While developing the mode of transport should pay attention to expansion of hinterland. On the basis of identifying the current situation and existing' problems of Ningbo's sea and railway transport market, the government should improve the collection and distribution system and build multimodal transport network system. In addition, the port needs to try its best to develop freight market, exploit port potentialities and build self-brand. In a word, Ningbo must seize the rare opportunity to be more competitive and rail-sea intermodal transportation in the city will enjoy an unprecedented prosperity in the future.

\section{References}

[1] Cao Yuanyuan, Jia Chunmei. Strategy Analysis of Ocean - railroad Transportation in Ningbo $[\mathrm{J}]$. Journal of Ningbo University of technology, 2011(1):54-59. 
[2] Wang Junfeng. Hinterland development and construction of multimodal transport system in Ningbo [J]. Logistics Technology, 2005 (9):16-18.

[3] Gong Yaojun. The development of the rail transport to promote the development of modern logistics industry in Ningbo - Zhoushan Port [J]. Port logistics, 2012 (12):39-41.

[4] Wutie Feng, Zhu Xiaoning. Development program of container sea and railway transport [J]. Beijing Jiaotong University, 2011 (2): 27-32.

[5] He Xiangyang. Development strategy and positioning of international container sea and railway transport in Ningbo [J]. Containerization, 2010 (7) :22-24. 